\title{
DE GOTA EM GOTA: VIOLÊNCIA, TEMPO E TROCA EM URABÁ, ${ }^{1}$ COLÔMBIA
}

Silvia Monroy

Após o culto da Igreja Cristã Trinitária Quadrangular, uma das mulheres veio em minha direção. Deu-me um forte abraço e presenteou-me com um sorriso, enquanto dizia que eu era muito bem-vinda em Urabá. Disse-me também que, a partir daquele momento, eu poderia contar com ela. Convidou-me então para ficar em sua casa, localizada na calle de la masacre, topônimo usado no dia a dia de uma forma tão surpreendente para mim como corriqueira e singela para as pessoas de lá. Ela insistiu que Urabá é um lugar "bom", amañador [aconchegante], mas, além deste fato, afirmou gostar de fazer novos amigos, vindos de outras terras. Entusiasmada, deixei que a emoção transmitida por Ivete fosse um dos meus guias naquele começo da experiência em campo, em 2009.

Rapidamente fui integrada à rede social formada por pessoas vinculadas ao/pelo evangelho. Minhas primeiras caminhadas pelos bairros foram feitas em sua companhia. Começou a impactar-me, durante aquelas jornadas, a quantidade de centros de oração e igrejas cristãs de diversas denominações e sua repentina aparição. Foi justamente na sala de uma casa-igreja que participei, conduzida por Ivete durante minha segunda semana na região, de outra cena que ficou na memória e que, com o passar do tempo, se tornou um índice acerca do caráter de Urabá.

$\mathrm{Na}$ frente da casa de um jovem pastor que se negou a falar comigo, achando que talvez eu fosse infiltrada da guerrilha, uma moto irrompeu violentamente na tentativa de contornar as poças e as crianças que jogavam bola na quadra do bairro. Por muito pouco a moto não ficou atolada na lama e o motoqueiro não caiu no chão. O riso de Ivete, da mãe, dos irmãos e sobrinhos do pastor tornou-os cúmplices naquele instante e delatou certa satisfação pelo que estava ocorrendo com aquele homem.

A minha cumplicidade surgiu de uma maneira espontânea e, portanto, também ri da situação, de forma semelhante àquela de quem ri contagiada pelo riso dos outros, sem imaginar bem por quê. Meu riso, no entanto, foi 
ofuscado por uma repentina preocupação: a camisa polo azul celeste do motoqueiro. Certamente não foi a cor o que chamou a minha atenção e sim a braçadeira com a bandeira da Colômbia (amarelo, azul e vermelho) nascendo do ombro direito, simulando as usadas indistintamente por policiais, militares, guerrilheiros e paramilitares em diferentes épocas. O olhar rápido confirmou que se tratava, efetivamente, da bandeira da Colômbia. O medo de estar perante um paramilitar, em um território considerado ainda sob o domínio paramilitar e das bandas emergentes ou bandas criminales (BACRIM), trouxe ironicamente imagens de guerrilheiros fardados das Fuerzas Armadas Revolucionarias de Colombia (FARC), com uma braçadeira nas cores da bandeira nacional. Depois veio a imagem - um referencial mais recente - de alguns paramilitares fotografados para os cartões-postais das desmobilizações coletivas após 2004.

"Ele é um para" foi a minha conclusão precipitada, que revelava o poder dos estereótipos e dos signos vinculados à guerra e atribuídos a regiões como Urabá: ${ }^{2}$ uma camionete branca, uma moto de alta potência sem placa, um súbito corte de energia elétrica, um desconhecido que transita por áreas dominadas por um grupo armado, uma desconhecida sem vínculos institucionais facilmente comprováveis. Naquele momento, assustada, contive a pergunta sobre quem era ele.

O homem desceu da moto, chegou até a porta daquela casa transformada em igreja cristã e perguntou pela mãe do pastor. Por um momento, eu fechei os olhos esperando o pior desenlace. Ela acenou, mas ficou séria enquanto todo mundo permanecia em silêncio. Confiante, falando alto, mandou-o embora dizendo que, se ela não tinha conseguido dinheiro para a comida do dia, muito menos ia ter condições de pagar a parcela. De uma forma displicente pediu para voltar no dia seguinte, porém, garantiu que pagaria. Ele guardou os cartões que segurava na mão e foi embora, reparando na minha presença com um olhar desconfiado. Quando saiu, consegui perguntar a Ivete quem era. A resposta dela foi rápida e sem explicações: "Ele é um gota a gota".

A cena que acabei de descrever é corriqueira na vida dos bairros de Urabá, como eu mesma comprovei durante meus percursos incessantes pelas ruas de Apartadó. Em menos de um mês esse tipo de evento já era familiar para mim; repetia-se diariamente da mesma forma. Posteriormente, consegui determinar que os "gota a gota" são personagens encarregados de uma modalidade de empréstimo de dinheiro que impõe juros muito altos. O prestamista pode cobrar juros equivalentes a $10 \%$ ou $20 \%$ do capital emprestado. No entanto, o pagamento em parcelas diárias disfarça a usura de uma maneira eficaz. No caso da compra de mercadorias, os devedores 
pagam aos cacharreros ${ }^{3}$ - que não são necessariamente "gota a gota" mas também em parcelas diárias, até três vezes o valor original do produto. Apesar disso, as pessoas entram nesse sistema de troca cientes dos altos juros e da especulação decorrente dessa circulação de mercadorias. As razões sintetizam-se em expressões como: "A gente faz isso por pura necessidade", "quando ninguém pode emprestar, os únicos que podem são eles", "os bancos não emprestam aos pobres, e eles sim", "só desse jeito a gente pode comprar as coisas", "quando a gente está apertado, é o gota a gota que salva".

O vínculo dos "gota a gota" com os grupos paramilitares e com as bandas criminales (BACRIM) ${ }_{1}^{4}$ como foi a minha suspeita inicial naquela cena, ainda é nebuloso, sobretudo porque é um assunto interditado nas conversas cotidianas. No entanto, diz-se que muitos "gota a gota" são desmobilizados das Autodefensas Unidas de Colombia (AUC). ${ }^{5}$ Eles teriam colocado em circulação o dinheiro que acumularam antes da desmobilização, assim como a quantia recebida como ajuda econômica para sua reintegração à sociedade. Em ambos os casos argumenta-se que é uma atividade econômica que visa à obtenção de uma renda que, de qualquer forma, está conectada, direta ou indiretamente, às atividades, principalmente no tocante à cobrança, de grupos armados ilegais presentes na região até hoje.

Isto me afirmaram as mulheres com as quais convivi durante meu trabalho voluntário no Banco de La Esperanza, único espaço onde consegui indagar sobre este assunto difícil de abordar. Uma delas estimou que $90 \%$ dos "gota a gota" são desmobilizados das AUC; os 10\% restantes são habitantes da região que têm dinheiro à vista, disponível para colocá-lo em circulação. Essas pessoas, no entanto, pagam uma taxa aos grupos armados, dedicados, por sua vez, à cobrança aos devedores. Passaram-se vários meses antes de eu perguntar o que acontece às pessoas que não pagam a um "gota a gota". Segundo depoimentos de várias mulheres, essas pessoas podem ser despejadas, desterradas ou assassinadas.

Quando tentei averiguar o número de "gota a gota" e de casas de empréstimos existentes em Apartadó, uma beneficiária do Banco respondeu: "Só na minha rua, perto de casa, eu conheço dois. Imagine como será no resto de Urabá! O que acontece é que a gente não fala sobre isso. Você sabe como é Urabá... sempre pode esquentar...". A expansão dessa modalidade de troca foi um fato que constatei vivamente, apesar de não ter conseguido aprofundar as causas do fenômeno a partir de uma perspectiva sociológica, por exemplo. Contudo, a presença dos "gota a gota" e a cena da cobrança diária, em especial, que ainda se repete na minha mente com diferentes rostos, foram fatos recorrentes e, em termos etnográficos, sinais da relação entre violência, tempo e troca. 
Explico. A cena relatada está localizada no presente, aquele que se refere ao dia de hoje - da parcela diária, da cobrança diária, do pagamento diário, da obrigação diária - mas ela se repete de forma recorrente todos os dias. Ela é, portanto, um exemplo da orientação dirigida ao que chamo de um "presente permanente", relativa a uma propensão, tendência, inclinação ou predisposição para viver a vida na sua atualidade. Esta orientação, em princípio temporal, mas também cosmológica e englobadora, perpassa e norteia a maior parte da vida das pessoas em Urabá.

O "presente permanente" é certamente um efeito da submissão prolongada à violência, como ocorre há quatro décadas em Urabá, sendo que a violência pode ser vivida como repetição ou como irrupção,mas sempre no patamar do presente. Contudo, como forjei a ideia de um "presente permanente" a partir de uma suspeição em relação às trocas, aos empréstimos e às cobranças, ela pode ser definida também como uma concepção de tempo centrada em pessoas ou acontecimentos cujas relações estão cruzadas por intermediações violentas, que revela, por esse viés, as relações de intercâmbio e as sociais de uma maneira mais abrangente, configurando uma espécie de "orientação para o mundo" (Tambiah 1996).

Com este objetivo em mente, comparo neste texto esta modalidade imposta pelos "gota a gota" com a experiência como voluntária no Banco de la Esperanza. Mediante este contraste, passo a analisar a relação entre o que denomino "presente permanente" e determinados aspectos da troca em Urabá, a saber: "o costume de ficar devendo", "a necessidade de pedir emprestado", e o imperativo de que "tudo deve ser dado". Coloco assim em destaque a relação entre violência e "economia", vínculo que costuma ser relegado ao campo da ilegalidade. No caso estudado, tais efeitos são aspectos primordiais da vida coletiva e da reprodução social.

\section{O Banco de la Esperanza ${ }^{6}$}

O fundo rotativo Banco de La Esperanza foi um projeto destinado, em larga medida, a amenizar os efeitos da troca vinculada aos "gota a gota" entre populações deslocadas, banidas de suas terras, ou desplazados, que se instalaram nos bairros das áreas urbanas de municipalidades de Urabá, como Apartadó, Turbo, Carepa e Chigorodó durante a primeira década do século XX.

Em 2009 a 2010, durante o trabalho de campo, a região estava sob controle das estruturas legadas pelos grupos paramilitares após a desmobilização das AUC. Esse controle, portanto, limitava meus percursos em Urabá. Como os 
efeitos do domínio do território por parte de grupos armados são mais evidentes nas áreas rurais - especialmente naquelas regiões que têm plantios de coca ou que são enclaves-chave para as rotas do narcotráfico e contrabando de armas - a pesquisa limitou-se aos povoados urbanos. Transitar nas áreas rurais localizadas ao sopé das serras ou cobrindo terras montanhosas, consideradas área de influência guerrilheira, das FARC, foi inviável.

Fui cautelosa, depois de advertida acerca de algumas perguntas, como, por exemplo, sobre os "donos" de fazendas e plantações, empresas, lojas e outros empreendimentos. Contornei esta dificuldade elegendo temas como orientações religiosas e me envolvendo como voluntária em vários projetos. Assim consegui percorrer Urabá, durante os primeiros quatro meses de campo, como voluntária do Banco de la Esperanza.

O Banco surgiu em 2003 com empréstimos entre 800 mil e 1 milhão de pesos (entre $\mathrm{R} \$ 900$ e $\mathrm{R} \$ 1.200$ em 2014). A maioria dos beneficiários dos primeiros empréstimos, incluindo os membros da diretoria de uma incipiente associação, não pagou nenhuma parcela dos créditos adquiridos. Após essa experiência frustrada, as Hermanas de San Juan Evangelista foram chamadas a gerenciar o Banco, mas foi somente a partir de 2009 que se instaurou a modalidade de microcrédito, ou seja, empréstimos entre 250 mil e 300 mil pesos. Naquele momento, a carteira de devedores havia atingido os 35 milhões de pesos e as instituições financiadoras não pretendiam dar continuidade ao projeto, isto é, não havia perspectiva de novas liberações de verbas.

As Hermanas Juanistas, vizinhas dos próprios beneficiários no bairro Obrero em Apartadó, foco transversal da violência em Urabá, criaram algumas alternativas para tentar salvar o projeto que, na visão delas, tem ajudado principalmente mulheres chefes de família afetadas pelo deslocamento e o desterro, pelo assassinato de seus companheiros e filhos, pelos custos decorrentes, e em situações de exílio de seus familiares. De fato, a base da renda de muitas delas é obtida a partir da venda de comidas prontas - tamales (pastéis de massa cozida de milho ou arroz com diferentes recheios de carne e legumes), fritos (salgados fritos), arepas (tortilhas de milho), doces de coco e saladas - ou da venda de peixe, galinhas, frangos e queijo. São estas, por conseguinte, as modalidades de empreendimento mais comuns.

As Hermanas criaram vários estímulos para que o projeto sobrevivesse. Entre eles, a possibilidade de um novo empréstimo, quando os beneficiários pagam todas as parcelas com os juros correspondentes - estes "têm as portas abertas no Banco". Outro incentivo é a dispensa da última parcela se o beneficiário tiver pago as demais na data certa.

Apesar desses estímulos e das modificações e ajustes ao longo dos anos, as Hermanas Juanistas, no seu papel de gerentes, têm evitado reportar de- 
vedores a bancos de dados de crédito de consumidores, empresas e grupos econômicos, ${ }^{7}$ assim como resistem à cobrança via processo jurídico, à exigência de fiadores ou de um contrato mais estrito. Evita-se a expropriação de pertences como forma de cobrança e, inclusive, desistiram de contratar um cobrador. Em anos anteriores o cobrador fez parte de uma estratégia, tida como positiva, por ter possibilitado a arrecadação das parcelas atrasadas de alguns devedores.

O gerenciamento do Banco vai, desse modo, na contracorrente das condições de troca, baseadas no medo e na ameaça, instauradas pelos "gota a gota". Os juros cobrados pelo Banco, equivalentes a 1,8\% mensais com parcelas quinzenais, buscam garantir a sobrevivência do fundo e do próprio projeto, mas também fazem parte de uma tática contra o paternalismo. Por esta razão, os empréstimos não são simples doações, mas implicam dívidas reais com o Banco. Assim, o projeto pretende restaurar a confiança em pessoas unidas por relações sociais deterioradas pelas experiências violentas e de deslocamento.

Meu trabalho como voluntária consistiu na realização de visitas domiciliares aos beneficiários do projeto com o propósito de avaliar suas condições de vida e as possibilidades de pagamento ou, dito de outro modo, as possíveis razões para a não retribuição ao Banco. As visitas foram concebidas, junto com as palestras subsequentes, como ferramentas em prol da transformação das práticas que estavam contribuindo para a extinção do fundo, e indiretamente para evitar a perpetuação do esquema dos "gota a gota".

Antes do começo das visitas que fiz, no início de 2010, recebi uma lista das pessoas cuja solicitação havia sido aprovada. De fato, realizei algumas visitas quando os cheques já haviam sido entregues e as pessoas estavam começando a trabalhar em seus empreendimentos. Também visitei as que já tinham pedido empréstimos, mas que, por conta de sua assiduidade e pontualidade, tornaram-se clientes preferenciais.

Conhecer de perto a situação daquelas famílias era um dos objetivos fundamentais, junto com a prerrogativa do acompanhamento do andamento das propostas. No entanto, o estímulo ao pagamento era somente uma das faces da moeda; a outra, o reverso, isto é, a interpretação que as pessoas faziam do meu trabalho, remetia ao espectro da dívida e, por conseguinte, da cobrança. Por isso, em larga medida, no decorrer dos encontros e das visitas às famílias, as mudanças de endereço, a troca de números telefônicos e a alteração do caráter dos empreendimentos eram constantes e refletiam o cerne do problema do Banco: uma resistência ao pagamento que me foi explicada como "o costume de ficar devendo". Posteriormente, esta máxima foi mencionada de outra forma pelos próprios participantes do projeto, tornando-se complexa e ao mesmo tempo ainda mais reveladora: "As pessoas não pagam ao Banco 
porque em Apartadó todo mundo está dizendo que eles emprestam dinheiro e nada acontece com quem não paga". Não acontece nada, certamente, no sentido de o devedor não ser ameaçado, banido ou morto.

Uma pergunta-chave durante as visitas correspondia aos envolvimentos com os "gota a gota". Das 25 pessoas visitadas, ${ }^{8}$ somente seis reconheceram ter feito empréstimos de dinheiro com eles. Esta porcentagem pode ter sido maior, visto ser este um assunto interditado no dia a dia. De modo geral, as pessoas não gostam de falar a esse respeito e as opiniões ancoram-se na exposição das situações-limite que os levaram a entrar nesse circuito de troca: doença, pressão por parte dos grupos armados para a saída urgente de algum membro da família da região, falta de dinheiro para pagar os serviços públicos ou para cobrir outras dívidas; estes últimos eram os argumentos menos frequentes ou, pelo menos, menos utilizados. As próprias Hermanas Juanistas explicaram-me, na tentativa de justificar as decisões de seus vizinhos que não resistiram aos "gota a gota", que as pessoas costumam fazer empréstimos de quantias que permitam concluir o pagamento da dívida em um mês, mediante parcelas diárias inferiores a 10 mil pesos, principalmente em casos de "emergência" ou "necessidade".

As pessoas visitadas que garantiram não ter feito empréstimos com os "gota a gota" diziam, por seu turno, que um negócio apoiado por eles vai facilmente à falência: "El gota a gota lo sala a uno" ["O 'gota a gota' dá azar"]. Daí o nome "gota a gota": "De gota en gota, usted se desangra" ["De gota em gota você se esvai"] — concluiu uma das clientes mais antigas do Banco, uma das boas pagadoras.

É preciso levar em consideração que, dentro do grupo de 25 pessoas visitadas, a metade passou pela experiência de deslocamento e desterro mediante o terror e a extorsão em algum momento de suas vidas. Na maioria dos casos, estas são as razões que explicam por que se assentaram naqueles povoados. Afora estes casos, sete pessoas do grupo fizeram referência, durante nossas conversas, à sua condição de migrantes em busca de terra e oportunidades de emprego. Mas até mesmo aquelas que garantiram nunca ter lançado mão dos "gota a gota", reconhecendo explicitamente o perigo, a usura e a iniquidade do esquema, salientaram que tomar estes empréstimo será uma opção sempre cogitada. Em tais transações, o imperativo é o pagamento sob diferentes modalidades de cobrança, incluindo a ameaça de morte ou a expulsão - isto é, o exílio de Urabá - sendo que essas pessoas (beneficiárias do Banco) já tinham sido banidas e expropriadas anteriormente, até mais de uma vez.

O imperativo de "pedir emprestado" valida a possibilidade oferecida pelos "gota a gota" e legitima a alternativa de ativar o Banco de la Esperanza, mas o "costume de ficar devendo" se torna conspícuo quando a cobrança 
não é viabilizada pela ameaça. Esta, por seu turno, envolve um retorno, no presente, a uma experiência violenta ocorrida no passado. Até mesmo o passado recente de ocupação irregular daqueles bairros deixou uma lei que comanda as trocas - e as relações sociais, de modo geral - mas naquele presente que se repete dia após dia: "Lo mio es mío, lo tuyo es tuyo, pero yo te puedo sacar de lo tuyo" ["O meu é meu, o teu é teu, mas eu posso tirar do que é teu]".

Deste modo, a perda termina por se constituir no alicerce da troca entre essas populações que têm sofrido ondas de massacres e assassinatos seletivos durante décadas. Contudo, o "costume de ficar devendo" e a própria dívida são mecanismos de compensação por uma perda percebida como originária. Poder-se-ia dizer que a violência primeira não está no vínculo social, senão no temor do rompimento do vínculo, no medo do abandono, que seria a ruptura definitiva (Godbout 1999). O abandono em Urabá tem diferentes faces: desterro, deslocamento, morte, exílio e desaparecimento. É por esta razão que o pagamento das dívidas não é imperativo. A leitura de Mauss poderia sugerir que as dívidas permitem a manutenção e a perpetuação do elo social, mas são eventualmente pagas quando a ameaça e o abandono são iminentes.

Durante esse processo, a perda é o pressuposto da troca e da própria dádiva, e o "presente permanente", noção de tempo englobante, inibe a retribuição. Estes dois alicerces, ou até efeitos, legados pela prolongada exposição e submissão à violência, estão por trás da expressão: "O meu é meu, o teu é teu, mas...".

Em Urabá, supõe-se que todo mundo entra no circuito de troca perdendo, o que é uma constatação das dificuldades na reprodução e na manutenção das relações sociais. Em decorrência disso, a cobrança violenta termina sendo uma espécie de motor substituto das relações, ou seja, o artifício que permite a validação momentânea de outros tempos que não somente o presente, pois remete ao menos ao momento da transação. A cobrança localiza-se também no campo da experiência violenta e de seus efeitos na troca, desafiando o lugar comum de que, para falar da experiência violenta, é imprescindível o testemunho do ato atroz.

\section{Sobre Mauss e a perda}

Rosa disse-me um dia, durante uma visita domiciliar, que um sacerdote católico quase fora assassinado porque fiava os casamentos. Ela concluiu que, em Urabá, ninguém pode emprestar nada, porque as pessoas têm o 
costume de ficar devendo. Esta situação me faz pensar que a universalidade das três etapas (dar-receber-devolver), caracterizadas por Mauss para explorar questões de teor cosmológico, ${ }^{9}$ sofre aqui uma distorção: uma vez cumpridas as duas primeiras etapas do modelo maussiano, a terceira não é completada. Dito de outra maneira, o tempo ${ }^{10}$ correspondente à devolução é anulado pelo presente, e mais evidenciado nos atos de dar e receber.

O erro do padre, na situação narrada por Rosa, foi ter "emprestado", isto é, ter efetuado os casamentos, e só depois cobrado, relembrando o compromisso adquirido no ato de receber aquela suposta dádiva. A cobrança posterior, passado o tempo da entrega — sem a rotineira ameaça ou extorsão - foi um atentado contra o tempo presente dos atos de dar e receber. Em Urabá, tudo deve ser dado, até porque previamente alguma coisa foi tirada, expropriada ou usurpada com violência.

Por outro lado, a ameaça, uma das formas de cobrança mais frequente, não se fundamenta, ou não lembra, o compromisso feito. O compromisso não é a base da troca mas sim a tendência ao abandono, à proximidade da perda: uma nova perda do devedor permanente, cujos efeitos são ainda mais devastadores se a cobrança apela para o medo que já está enraizado.

Indo um pouco mais adiante: na proposta maussiana, o tempo que transcorre entre o recebimento e a retribuição deixa o donatário à mercê do doador, em um estado de dependência emocional. A cobrança situa-se, assim, no cerne desta dependência, na face do medo do abandono, fertilizada pelo terror das décadas conhecidas como la época de la violencia, correspondente à incursão e à consolidação paramilitar nos anos 90 . Na minha compreensão de Mauss, ${ }^{11}$ a retribuição faz com que a igualdade em dignidade, na qual se baseia o circuito, volte ao ponto inicial. No caso apresentado, a precedência da perda como pressuposto da troca e a inibição do passado e do futuro implicam uma desigualdade em dignidade que é reproduzida segundo a ótica da oposição vítima-algoz, por exemplo. Se o presente é quase sempre um tempo permanente para as pessoas em Urabá, a retribuição, o ato de devolver, é a etapa sacrificada do ciclo.

Voltando à experiência etnográfica, lembro-me de que um dos aspectos fundamentais dos cursos de empreendedorismo prévios à entrega dos cheques pelo Banco de la Esperanza era a elaboração e o manejo dos livros de contas, que visavam ao controle das entradas e das saídas de dinheiro. Esta era uma forma de socializar os beneficiários quanto à possibilidade de quantificar o ganho e a evolução de suas empresas. Durante as visitas, eu devia registrar, inclusive, se estas pessoas tinham livros de contas e, além disso, devia comprovar se estavam utilizando os livros de maneira adequada. 
Apesar de estar fora da minha alçada a avaliação da utilização dos livros contábeis, comprovei que, do grupo de 25 pessoas, somente cinco tinham um caderno com algumas contas, incluindo listas de pessoas ou clientes. Desse subgrupo, apenas o dono de uma marcenaria, um paisa, ${ }^{12}$ oriundo das regiões meridionais do departamento de Antioquia, tinha um livro de contabilidade; os demais tinham um caderno, sem datas, no qual registravam todos os clientes, os bons pagadores e os devedores.

Uma das mulheres deste grupo exibiu com orgulho seu "caderno de contas", e com um ar confiante disse-me: "Olhe, meu negócio vai bem. Ninguém me deve, não estou perdendo". As minhas perguntas, claramente infelizes, impediram a continuação da nossa conversa, pois indaguei se ela sabia o valor do lucro, e se por acaso tinha claro quanto do dinheiro já arrecadado ia ser usado na compra de materiais para recomeçar o ciclo. A resposta que obtive foi o silêncio.

"Regar"13 é outra expressão recorrente nas respostas, quando eu tentava avaliar o estado do empreendimento. Ouvi frases como "ya regué marrano por el barrio", "regué todo el queso, me fue bien", "regué la mercancía, ahora tengo que empezar a recoger". ["Já espalhei porco pelo bairro", "espalhei todo o queijo, me dei bem", "plantei a mercadoria, agora preciso colher o que plantei"]. Este tempo entre os atos de "regar" e colher é imprevisível, impreciso. Em suma, a não retribuição ao fundo rotativo decorre da resistência ao pagamento dos clientes do Banco. "Regar" abrange os momentos de dar e receber; "recoger" entra, de uma forma lacônica, na incerteza do futuro, negado pelo presente e viabilizado pelo sentimento de perda. Uma das mulheres que visitei disse-me que ela criou um fundo, uma espécie de poupança. O objetivo era, porém, impedir a perda causada por aqueles que fiavam e não pagavam (Aliás, em outra dimensão da vida social em Urabá, é comum que as pessoas falem sobre o familiar "que se perdió" para fazer referência ao desaparecimento forçado).

Durante a reunião preparatória da assembleia anual do Banco, perguntei à madre superiora qual é a reação das pessoas quando pagam as parcelas. Ela respondeu: "Eles expressam a satisfação por estar cumprindo. Uma senhora me disse: 'Perdi o que fiz no sábado, mas na próxima semana vou pagar'". Indico aqui, mais uma vez, que é a perda o princípio que alimenta o sistema.

No contexto de uma reunião com a participação de clientes antigas do Banco, uma delas manifestou a preocupação sobre o futuro do projeto: "Necesitamos recoger la plata que está regada en la calle" ["Precisamos recolher a grana que está espalhada na rua"]. Várias estratégias foram discutidas durante aquele encontro: a exigência de fiador, o recurso a bancos 
de crédito, e até mesmo a expropriação de pertences - principalmente eletrodomésticos. Mas não se chegou à almejada solução; dominaram as histórias de dívidas e devedores e de fiadores incautos. Uma das hermanas, já desanimada, confessou que sentia vontade de fazer uma lista com os nomes dos devedores, reproduzi-la e pregá-la nos postes dos bairros. Mas se deu conta de que esta seria a mesma estratégia que o grupo armado dominante pratica, duas vezes ao ano, no intuito de realizar a limpieza social, ${ }^{14}$ tipo de extermínio que vigora há mais de 30 anos na região. Uma fala vinda do fundo da sala foi definitiva para um retorno da esperança ao Banco, para a esperança de Urabá e até para a minha análise:

Irmã, a gente tem que definir a estratégia que vai ser adotada para recuperar a grana que está na rua e qual a estratégia para não seguir perdendo. Por exemplo, fazer as visitas sobretudo nos finais de semana, na sexta, no sábado e no domingo. Não é que você diga "me dê tanto", mas vamos ver quanto a gente recolhe.

Aqui, trata-se de ver a perda em sentido positivo, pois visa a uma ação contra sua perpetuação. Recoger, nessa situação, substitui a cobrança, especialmente a cobrança feita sob ameaça - "Não é que você diga 'me dê tanto'". Contudo, até nas propostas mais corajosas, vindas das mulheres engajadas com o Banco, os pressupostos locais relativos ao sistema de troca são ratificados como valores. Citando o caso de outro fundo rotativo de uma associação local de mulheres, uma delas propôs:

A pessoa que queira aspirar a um empréstimo deve assistir às assembleias durante seis meses. As próprias pessoas da assembleia são as cobradoras, ou seja, se ela encontra 20 mulheres na rua, as 20 vão dizer: "Você está atrasada, tem que pagar". Toda assembleia sabe onde você vive, o que faz, quem são seus filhos.

A iniciativa desta mulher, propondo que todas se tornem cobradoras para salvar o Banco, indica que a cobrança é um mecanismo que permite falar sobre aspectos que remontam a momentos diferentes do presente: ao passado recente e a futuras possibilidades. E o fato de ter expressado em público sua opinião sobre as vantagens de saber quem é a pessoa, o que ela faz e quem são os filhos é um acontecimento extraordinário neste tipo de cenário. Mas outro importante postulado é também enunciado aqui: para relacionar-se com alguém, é preciso saber quem são os filhos e não quem são os pais da pessoa em questão. O passado não tem o poder de identificar por meio dos antepassados, como é largamente vigente, mas sim pela descendência. Se os pais estão vivos, especificamente o pai, é porque "não 
deve nada", ou seja, conseguiu sobreviver. O que põe a vida em risco são os vínculos dos filhos, o que compreende suas ações no presente e suas dívidas, que geralmente são pagas com a morte. A atual geração é o eixo, o horizonte, o principal referencial, muito embora frágil, que leva à situação extrema de tornar a morte rotineira; ela não mais surpreende.

\section{Do homem-dívida ao homem-cobrador: confrontando a etnografia com algumas referências bibliográficas}

A universalidade do dom tem sido tema de discussão por outros autores. Caillé (2002) salienta que há sociedades organizadas ao redor da fetichização de um dos três momentos da dádiva. Independentemente do aspecto da fetichização, de fato é possível se imaginar uma distinção entre possíveis sociedades da dívida: um caso seria em que é imperativo estar sempre pagando; outro, sociedades da recepção ou da submissão, nas quais receber é o foco das ações; e sociedades da obrigação do dom propriamente dito, nas quais o foco é o esplendor da dádiva.

"O costume de ficar devendo" e a orientação de que "tudo deve ser dado" localizam Urabá no segundo caso. A submissão se dá, em primeiro lugar, pela via do terror e do medo, expressos nas ameaças de desaparecimento, exílio e morte. Minha experiência de campo resultou na imersão nos labirintos da vida no "presente permanente", um efeito daquelas formas de submissão. Este tempo tem seu alicerce na desconfiança e no medo, mas, paradoxalmente, também produz a euforia e a exuberância (ver Monroy 2013). A desconfiança é o principal par da perda, sobretudo quando ela se institui como paradigma das relações sociais. Neste sentido, Caillé indica que o modelo maussiano das prestações totais está vinculado à confiança total no outro, a qual possibilita, por sua vez, o equacionamento das noções de obrigação, liberdade, interesse e desinteresse. Por oposição, a desconfiança no outro - que tem um caráter total segundo o autor, pois ou se confia ou não, sem meio termo - gera um desequilíbrio desses elementos ou estimula sua manifestação hiperbólica e desfigurada.

A desconfiança é um dos efeitos da violência em Urabá, com seus períodos de massacres, e com seu presente de assassinatos seletivos, limpezas, desaparecimentos e sucessivos deslocamentos e desterros. Poder-se-ia mesmo afirmar que o "presente permanente" é vivenciado por meio do medo e da suspeição,embora tenha surgido da angústia dos momentos de violência exacerbada. Neste sentido, Sémelin (2009) esclarece que a angústia se caracteriza por ser difusa e imprevisível, enquanto a transmutação da angústia 
em medo concentrado, por intermédio de figuras hostis, por exemplo, pode resultar em um ódio pernicioso contra o outro. Ultrapassadas as primeiras angústias, o medo molda, junto com o ódio, um dos "compostos psicológicos mais estáveis", duradouros e eficazes na anulação de outros tempos de vida (2009:75). Assim, o pagamento somente pode ser concretizado mediante o medo da perda, do abandono, ou seja, mediante o amedrontamento ou através de uma intermediação violenta na cobrança.

Uma das hermanas disse-me que o perfil dos melhores pagadores é composto por mulheres "evangélicas"; entretanto, o grupo dos devedores é integrado também por homens (em geral maus pagadores) - que conformam uma minoria nas solicitações de empréstimo - e por mulheres chefes de família não "evangélicas". Cabe perguntar, então, por que as mulheres que "se entregaram aos pés de Cristo" são melhores pagadoras, tornando-se assim clientes preferenciais do Banco?

O temor a Deus, manifestado com frequência tanto nas conversas cotidianas como durante os cultos, escolas dominicais, jejuns e vigílias, pode ser uma possível pista. Alguns pastores acreditam que, além do respeito a Deus, o temor a Ele relaciona-se ao julgamento do pecado, do mal. Quando indaguei uma das mulheres sobre por que os "cristãos" têm mais compromisso com o pagamento das parcelas do Banco, a resposta foi: "É que quando você adquire uma dívida, a adquire também com Deus". Na versão local, o temor a Deus percorre a mesma trajetória que o medo. Por isto, argumenta-se também que o evangelho é tão individual como a salvação, só vai depender dos atos individuais, como acontece com o pagamento das dívidas.

Mais ainda: o temor a Deus, entendido como medo, possui o componente da submissão - "submeter-se a Deus". Esta é justamente a base do "evangelho como estilo de vida", um dos aspectos mais recorrentes nos diálogos e nas conversas com pastores e cristãos e, especialmente, com pessoas pertencentes a doutrinas trinitárias que se beneficiavam dos empréstimos do Banco. O estilo de vida do cristão é a explicação dada para a sobrevivência em Urabá, que também está relacionada ao pagamento das dívidas. Durante uma escola dominical, escutei o pastor pregando: "Pagar a Deus em uma só parcela em dinheiro é muito mais difícil, mas é o que devemos fazer". Se toda dívida é contraída com Deus, portanto, a cobrança é feita diretamente por Ele. Comportar-se corretamente é, então, a chave para não ser atingido pela violência. Durante uma visita, uma das beneficiárias do projeto afirmou: "Eu acho que são as próprias pessoas que buscam a violência; às pessoas boas nada acontece. Deus os livra".

O controle mediante o temor a Deus, a exigência e o cumprimento das regras e até a vigilância exercida pelos "irmãos" e "irmãs" são componentes de 
um estilo de vida considerado oposto ao do católico, focado na lassidão como norteador da vida e como atitude em relação às regras, especificamente. Até mesmo o sacerdócio é visto como distante do estilo de vida cristão, como se fosse "uma carreira, uma profissão", "como ser médico ou advogado", explicaram-me.

Se evitei antes a noção de fetichismo de Caillé, a mesma noção, quando utilizada por Taussig (1987), adquire outro significado. Sendo uma minoria dentro do conjunto dos beneficiários do projeto, os homens enquadram-se mais no papel de cobradores do que o de devedores, sobretudo quando vistos como "guerreiros" e não como "seguidores do evangelho". Os "guerreiros", como podem ser cobradores, têm liberdade de assumir o papel de devedores. Ao desenvolver sua noção de fetichização, Taussig detectou, durante o auge da seringa no início do século XX no sudoeste da Colômbia, que o sistema de aviamento fazia com que os homens se definissem por suas dívidas. Por conseguinte, neste caso, a dívida era o elemento "fetichizado". Já em Urabá, o homem é um "guerreiro", ${ }^{15}$ aquele que cobra as dívidas de terceiros mediante o medo e o terror. Ele pode cobrar o que outros lhe devem, e pode também cobrar perdas sucessivas já sofridas. Esse processo de reprodução do ódio e da vingança é reforçado constantemente pelo impacto ideológico de uma perda originária. Assim, neste contexto, é a perda o elemento "fetichizado".

Em Urabá, tudo se passa como se a perda antecipasse o intercâmbio e a cobrança fosse, portanto, legítima. Assim, em uma das reuniões das beneficiárias do Banco, nas quais raramente os homens marcavam presença, uma mulher disse que o ideal é sempre mandar um cobrador, "um homem", para que "faça este trabalho", recusando-se ela mesma a fazê-lo, como alguém havia sugerido. Um funcionário de uma ONG local, que havia apoiado o projeto, comentou que graças a "eles" o projeto havia sido repensado, uma vez que tinha sido adotada, naquela época, a figura do cobrador.

A dívida em Urabá é, assim, a constatação da perda no tempo presente, no dia de hoje. E se, no caso do sistema de aviamento, o fetichismo da dívida é um reflexo da elaboração cultural do medo, o fetichismo da perda, que se reproduz em um "presente permanente", é outra trajetória desse mesmo processo no espectro da guerra e da sobrevivência. Em ambos os casos, o medo que se impõe é o elemento que permite o controle de populações massivas, fora o terror naturalizado das práticas in loco.

\section{A doação e o pagamento dos mortos}

Em Urabá, a precedência da doação está plasmada no pressuposto de que todos estão acostumados a que "tudo seja dado". ${ }^{16}$ Mas uma dádiva intei- 
ramente compulsória não é mais uma dádiva (Godbout 1999:124). Pedir emprestado de maneira compulsória - "a necessidade de pedir emprestado" - quando existe "o costume de ficar devendo", é resposta a dádivas igualmente compulsórias. A doação, vista como dádiva, pode produzir uma paridade entre parceiros de uma relação consolidada, mas a princípio cria uma profunda diferença que pode se tornar duradoura, como as marcas das experiências violentas e de deslocamento, especialmente quando a retribuição é inibida. Compartilhei a frustração de uma das hermanas quando me contou sobre o encontro fortuito que teve na rua com uma cliente do Banco, boa pagadora, e a viu cansada, suada e desanimada. Ela disse-lhe: "Irmã, andei por todo o Apartadó e ninguém me deu nada". Meses depois, li em um jornal local o depoimento de uma vítima das enchentes de 2010, moradora de uma área de risco com assentamentos de populações deslocadas e desterradas: "Tudo o que a gente ganha, a gente volta a perder".

Os dons são veneno e remédio, benefício e desafio. Do ponto de vista de uma teoria da ação, engendrada no seio do "Ensaio sobre a Dádiva", poder-se-ia pensar em dois tipos de dom (Caillé 2002) — que eu leio como doação - próprios de uma articulação positiva de interesse, liberdade, espontaneidade e obrigação: o dom a outrem, e o dom de criação. O primeiro é resultado de um reconhecimento do outro que se opõe ao mero interesse. Aliás, o interesse é uma categoria da ação que tem perdido o teor político pela primazia do cálculo econômico financista. No segundo caso - dom de criação - liberdade e espontaneidade opõem-se à obrigação e à lei. Quando a dádiva torna-se veneno e não remédio, os dois tipos de dom estão ausentes. A perda impõe-se, assim, contra a articulação de doação e obrigação, perde-se a espontaneidade e se exaltam o interesse e a obrigação. Anulam-se, por esse viés, as possibilidades de estabelecer novos pactos sociais.

A caridade pode ser compreendida, neste contexto, como a rivalidade pelo dom. O avanço do processo de reparação administrativa, contemplado na Lei de Justiça e Pazem 2008 (ver nota vi) foi acelerado ao final do mandato de Álvaro Uribe Vélez (2002-2010), incluindo a entrega das indenizações como parte da Acción Social. ${ }^{17}$ A indenização solidária, que era equivalente, nos casos de homicídios e desaparecimento forçado, a quase 20 milhões de pesos - aproximadamente $\mathrm{R} \$ 23 \mathrm{mil}^{18} \mathrm{em} 2014$ - era referida com a expressão "Pagar o morto". De fato, era muito comum ouvir-se: "Já me pagaram meu marido"; "já me pagaram meu pai"; "já me pagaram meu irmão". Era também comum ouvir os mesmos enunciados em forma de pergunta: "Já te pagaram o teu pai?"; "Já te pagaram teu marido?"; Já te pagaram teu irmão?".

Brigas entre irmãos, esposas, amantes e companheiras de uma mesma vítima passaram a ser comuns, conflitos que se estendiam aos filhos. Algumas 
mulheres à espera do pagamento condenavam outras que haviam gastado tudo o que receberam, fazendo novas dívidas. Ao mesmo tempo, evitava-se falar sobre o recebimento da indenização porque provocava mais pedidos de conhecidos e "depois ninguém vai querer pagar porque é a grana do governo". Algumas comentavam que, pelo fato de o marido ter sido assassinado pela delinquência e não pela guerrilha ou pelas AUC, "não vão pagá-lo". Outras perguntavam-se: "Mas será que o governo tem tanta grana para pagar um morto três vezes? Por que então irão pagar a todas as mulheres cujos maridos foram mortos?".

Em diferentes encontros e reuniões de vítimas, elas repetiam a questão do pagamento dos mortos, no meio da euforia da indenização. A plateia dividia-se, automaticamente, no grupo das pessoas que foram indenizadas e naquele que ainda estava à espera do recebimento. Até os eventos fortuitos, e trágicos, do cotidiano eram enquadrados nessa expectativa. Dias depois de um acidente de trânsito, no qual morreu uma menina de 10 anos, surgiu o boato que ela era filha de um coronel do Exército. O boato foi espalhado durante uma reunião; uma das mulheres que acabava de ouvi-lo comentou: "Se era filha de um coronel, então irão pagá-la pelo resto da vida".

Este pagamento, que não supre a dívida, na medida em que não restaura a perda nem elimina o medo do âmago das relações sociais, pode ser uma "dádiva-veneno", ou seja, uma dádiva compulsória que impede a conquista de autonomia. Evapora-se a obrigação intrínseca ao dom, que é uma exortação à ação (Arendt 1978). Impede-se que a dádiva seja vivida como um sistema que incita as pessoas a aumentarem a liberdade dos outros (Etzioni 1988). Contudo, a dádiva é uma experiência que evidencia a tensão entre indivíduo e grupo, e entre liberdade e obrigação. A dádiva-veneno, portanto, está relacionada à exacerbação do componente de individuação, ${ }^{19}$ que termina servindo para reforçar a individualização no grupo: fomenta uma libertação dos outros, mas é estéril em grupos de pessoas submetidas aos efeitos da violência. Seus componentes podem ser enunciados como a perda, o medo, a desconfiança e a anulação de outros tempos de vida, como o passado e o futuro.

Na minha leitura, Strathern (2006 [1968]:329) dá algumas pistas para compreender esses processos de individualização relacionados com a dádiva. Ela é definida como uma técnica de objetivação e de personificação na qual os objetos das relações sempre são outras relações. Contudo, as dádivas seriam imagens do possível colapso, ruptura, de qualquer relação de separação entre causa e efeito. A importância da relação causa-efeito diz respeito à singularidade da ação do sujeito. E é mediante a singularidade de sua ação que um "agente" pode manter separados os momentos de causa e 
efeito. Por isso, quando a doação se converte em dádiva-veneno, impede a identificação da singularidade da ação, gerando uma perda de autonomia, por um lado, e uma individualização do interesse, por outro.

A Lei de Justiça e Paz focaliza amplamente a reparação individual, contemplando a indenização solidária, a restituição de bens e de terra, a reabilitação e as garantias de que os fatos não se repetirão. De concreto, são os esforços para a indenização econômica e os trâmites para o pagamento que merecem maior atenção, revelando o perigo das reparações fundadas na dádiva-veneno. Obrigações sociais se transformam em obrigações contratuais, quase mercantis, impedindo o perdão que permitiria a superação do sistema da violência.

Para conciliar a maioria de conflitos, seria necessário fazer-se um gesto, um ato, não previsto nas regrais vigentes, a fim de propiciar outro estado das relações - caso "o outro" que está envolvido na relação aceite. ${ }^{20} \mathrm{E}$ Mauss ainda nos adverte, numa nota de rodapé do "Ensaio sobre a Dádiva", que os ritos de paz entre os Haïda, Tsimshiam e Tlingit consistem em prestações e contraprestações imediatas que são, no fundo, trocas de cauções e gestos que precisam da anulação do tempo de espera entre a entrega e a devolução para propiciar um estado diferente das relações, ou seja, uma série de condições ideais de confiança, liberdade, reconhecimento e dignidade.

\section{A "perdida" e os "gota a gota"}

A base epistemológica da etnografia nas últimas décadas tendeu a se centrar basicamente na confiança nas palavras. Tal tendência não só foi contra a tradição consagrada da antropologia, isto é, a lição de que se aprende e apreende via eventos, gestos, música e por todos os sentidos, como também representou uma aceitação tácita do nosso próprio senso comum, baseado na referencialidade da linguagem. Mas o discurso, os depoimentos, as falas, enfim, nem sempre são tão eloquentes quanto certos gestos que exprimem muito mais.

"Tirarse una perdida" [fazer uma ligação perdida] é um gesto com grande potencial etnográfico. Este foi um hábito local que Ivete me ensinou. Depois do nosso primeiro encontro na igreja que ela frequentava, comecei a receber ligações dela diariamente. Depois de dois toques, Ivete desligava. Nas primeiras ocasiões, eu tentava ligar de volta, achando que talvez ela não tivesse crédito e, por essa razão, deixava tocar apenas duas vezes. Após várias tentativas, ela atendeu e explicou que estava somente "tirando una perdida" para que eu soubesse que pensava em mim, que desejava 
que eu estivesse bem, que eu estivesse viva. Ao mesmo tempo, foi clara em explicitar que não esperava retorno. Algum tempo depois, nos finais do dia, meu celular sempre registrava várias ligações perdidas, e não somente de Ivete, mas também de pastores, jovens dos bairros, crianças, beneficiárias do Banco de la Esperanza etc. Eu já não atendia às ligações antes dos três toques, mas também tinha aprendido a "tirar perdidas" aos meus amigos e conhecidos em Urabá.

Neste gesto, após instaurado o código, reconhece-se a intenção que o motiva, mas a ligação de retorno é dispensada. Não há mensagem referencial, não se apela ao passado, nem se antecipa o futuro, apenas se reforça a relação atual entre duas pessoas por um ato fático. A eficácia é produzida sem palavras: o laço social fica registrado, a iniciativa existe, embora não se devolva o gesto de pronto. Mas há, de qualquer forma, um incipiente retorno à confiança.

Contudo, é um gesto no presente."Tirarse una perdida" resume-se, então, à ação aqui e agora, ao ato do próprio gesto. Em termos semióticos, a perdida é um conativo, ela chama - isto é, não está "perdida", apesar do nome. Tem o sentido de, pelo toque, identificar o remetente para o destinatário. Vejo a perdida como a máxima expressão do momento, uma expressão criativa no imediato, o impulso vital da necessidade de estar conectado, mas dispensando-se a reciprocidade imediata.

E, assim, volto ao presente permanente para encerrar.

Como vimos, fazem parte desta orientação ao mundo uma série de fatos etnográficos: a propensão aos pagamentos parcelados no dia a dia, a cobrança dos "gota a gota", a dificuldade de implementar contratos formais de empréstimos e mesmo a tentação do Banco de la Esperanza de lançar mão de cobradores. Incluem-se também os princípios analisados: o "costume" de ficar devendo e a expectativa de que tudo deve ser dado. Fica, aqui, em aberto a questão da possível especificidade dos sistemas de trocas monetarizadas ("gota a gota", bancos comunitários, microcrédito) e não monetarizadas (centradas no afeto, como as "perdidas"). No entanto, creio que em ambas as modalidades existe uma dimensão da afetividade, dos sentimentos, que ainda deve ser aprofundada. Em termos analíticos, contudo, estes dados ilustram um determinado tipo de relação de reciprocidade, aquele que vejo como dominante, uma reciprocidade que é abortada no ato de devolver. Também é preciso acrescentar que a orientação ao "presente permanente" não elimina totalmente o passado e o futuro: como vimos,o passado é o tempo do terror; já o nome do Banco remete a um futuro desejável. Mas passado e futuro são inibidos em face da exaltação do presente. E quando o presente é exacerbado, tem-se o cenário da sobrevivência, de uma perda constantemente revivida. 
Urabá não é o único caso da associação da violência com o domínio do presente. No México, Lomnitz-Adler (2003) analisa os efeitos da época conhecida como "La Crisis", que corresponde à hecatombe da economia nacional dos anos 80. Um dos efeitos estudados por ele é a "saturação de presente", isto é, a recusa da população a socializar imagens viáveis e desejáveis do futuro. Esta época é definida pelo autor como o momento de um espetáculo de ilusões quebradas que afetou a capacidade dos sujeitos de enfrentarem novas dificuldades, ao exacerbar a sensação de que o tempo está suspenso. Tal excesso de presente seria uma percepção histórica em que domina uma suspensão das expectativas que existiram no passado.

Expressões como "La Crisis" remetem a uma cadeia de eventos ou até mesmo a um período de tempo que são condensados e isolados na consciência coletiva como uma marca simbólica e temporal. Já em Urabá, as pessoas usam a expressão "la violencia" para se referirem à sangrenta década de 1990, confirmando que tudo é passível de ser "temporalizável", mas só é transformado em "tempo" aquilo que é considerado socialmente relevante pela coletividade em determinado momento. ${ }^{21}$ "La Crisis" envolve uma saturação de presente, enquanto o "presente permanente" é um componente de uma orientação que tem raízes em "la violencia", que legou a percepção de um estado de guerra permanente ou latente. Por isso, as histórias são declarações feitas no presente, no plano da sobrevivência, ainda que permeadas pela ideia de que o dia de hoje, a atualidade, é uma manifestação de sobrevida.

Um caso oposto é relatado por Crapanzano (1986). Durante sua pesquisa na África do Sul, encontrou, entre os "brancos" falantes de africaaner, uma peculiar forma de paralisia, centrada na espera de que alguma coisa aparecesse, ou algo acontecesse. A espera (waiting) era uma forma de orientação que exaltava o futuro. Mas esse futuro era restrito e restringia as possibilidades das pessoas no presente: o futuro criava, simultaneamente, ansiedade e esperança, e a retórica sobre o passado desaparecia.

Contudo, a comparação com o caso colombiano mostra peculiaridades: "esperar" foi um aspecto identificado por Crapanzano a partir do estrato dominante do país; no caso do "presente permanente", são pessoas em estado de submissão prolongada à violência. Ambas as ideias compartilham o potencial de exacerbar um aspecto da vulnerabilidade social num espectro amplo: enquanto o "presente permanente" alberga um impulso vital desenfreado e uma força criativa no imediato - como exemplifica o gesto da ligação "perdida" — o waiting é uma força fraca, passiva e entorpecida. No caso da África do Sul, porque se estava à espera de algo, era o passado que proporcionava a sensação de segurança; mas quando o presente se exacerba, 
como em Urabá, temos o cenário da sobrevivência, de uma perda originária constantemente revivida.

De gota em gota, a vida em Urabá é absorvida no seu dia a dia, sem garantias do amanhã, em um cenário de incertezas quanto à sobrevivência, talvez à espreita do terror, em que não se ousa sonhar com o futuro e a morte não surpreende. Durante a minha experiência de campo, a música mais ouvida e solicitada em rádios, bares e boates, e até um dos toques preferidos de celular, coincidência ou não, era a salsa interpretada pelo cantor Luis Enrique, chamada "Yo no sé mañana", ${ }^{22}$ da qual retiro alguns versos:

Para qué pensar y suponer, no preguntes cosas que no sé, yo no sé

Para qué jurar y prometer algo que no está en nuestro poder

Yo no sé lo que es eterno, no me pidas algo que es del tiempo.

Yo no sé mañana, yo no sé mañana

Quién va a estar aquín ${ }^{3}$

Recebido em 10 de setembro de 2013

Aprovado em 20 de outubro de 2014

Silvia Monroy é bolsista PDJ, CNPq, Universidade de Brasília. E-mail: <silviamonroy@gmail.com>

\section{Notas}

${ }^{1}$ Urabá é uma região da Colômbia localizada na fronteira com o Panamá. É reconhecida por ter um caráter triplo de fronteira. Além de fronteira internacional, com conexão marítima direta pelo Mar do Caribe e indireta pelo Oceano Pacífico através de rios e estradas rudimentares - que facilitam o tráfico ilegal de contrabando, armas e drogas - é uma fronteira interna regional que liga as dinâmicas de três departamentos: Chocó, Antioquia e Córdoba. Simultaneamente, é uma fronteira étnica, pois ali confluem grupos indígenas - Embera, Tule e Zenú, principalmente - populações negras e outras populações provenientes de regiões andinas do país. É uma região de aproximadamente 600 mil habitantes hoje, catalogada historicamente como uma das zonas mais violentas da Colômbia (Devido à complexidade do contexto, necessito incluir neste artigo longas notas para me referir a alguns personagens e eventos da história contemporânea da Colômbia e, especialmente, de Urabá). 
${ }^{2}$ Ainda que as guerrilhas do Ejército de Liberación Nacional (ELN) e do Ejército Popular de Liberación (EPL) tenham entrado em Urabá em 1966, e as Fuerzas Revolucionarias de Colombia (FARC) em 1969 (García 1996), o conflito fez-se brutal a partir do final da década de 1970, quando a mudança de estratégia concentrou-se nos sindicatos, infiltrados pelas guerrilhas. Morreram milhares de trabalhadores e operários bananeiros acusados de pertencer ou colaborar com o sindicato ou grupo armado oposto. Exército e polícia combateram suas ações, mas a conflagração foi iminente no meio do terror anticomunista ainda vivo ao qual se acrescentou o extermínio local e nacional do partido político de esquerda, Unión Patriótica (UP). Simultaneamente, na década de 1980, os carteles do narcotráfico criaram exércitos privados que, junto com iniciativas contrainsurgentes de comerciantes, fazendeiros, donos de gado, políticos e militares, desembocaram nas Autodefensas Campesinas de Córdoba y Urabá (ACCU) e nas Autodefensas Unidas de Colombia (AUC) em meados da década de 1990. Dessa maneira, os assassinatos seletivos e os massacres constituíram o reflexo de uma nova virada no conflito na Colômbia com a incursão dos grupos paramilitares confederados. Registraram-se em Urabá, por exemplo, 96 massacres na década de 1990, um por mês entre 1992 e 1993, e um a cada vinte dias entre 1994 e 1995 (Suárez 2007). Em menos de uma década de retaliações insurgentes e contrainsurgentes, diz-se, $10 \%$ da população de Urabá foram exterminados. No início de 2010, foram registradas 17 mil vítimas, correspondentes à época de consolidação do controle paramilitar (1997-2005) na região de Urabá.

${ }^{3}$ Cacharrero lembra a figura do mascate no Brasil.

${ }^{4}$ Sigla relativa à categoria bandas criminales que surgiu, conforme alguns analistas, durante o último ano do mandato de Álvaro Uribe (2009-2010) como alternativa para legitimar o polêmico processo de desmobilização das Autodefensas Unidas de Colombia (AUC), ocorrido entre 2004 e 2006, e respaldado pela Lei 975 de 2005 (Lei de Justiça e Paz). Afirma-se que muitas bases armadas daquela organização não foram desestruturadas e algumas delas têm se reciclado nas BACRIM. No primeiro semestre de2010, mencionava-se o conflito entre Los Urabeños, Los Paisas, Las Águilas Negras y Los Rastrojos (Human Rights Watch 2012). Estes grupos dedicam-se ao controle armado dos plantios, laboratórios, rotas e pontos de embarques de cocaína, e ao controle armado de outras atividades, como o contrabando e a mineração ilegal. Além disso, estes grupos espalhados pelo país inteiro - em cidades e áreas urbanas - buscam controlar o acesso das populações a bens e serviços, o comércio local e o transporte de passageiros e de carga. Usam como fachada a venda de serviços de proteção e segurança para cometer atos de extorsão vinculados, por sua vez, a ameaças, assassinatos e deslocamentos forçados de população.

${ }^{5}$ Os blocos das AUC que operavam em Urabá - Bloco Bananero e Bloco Élmer Cárdenas - começaram o processo de desmobilização de 2 mil membros da organização, entre 2004 e 2006, sob a tutela da Lei de Justiça e Paz. A Lei 975 de 2005, ou Lei de Justiça e Paz, facilita os processos de paz e incorporação individual e coletiva à vida civil de membros de grupos armados ilegais à margem da lei, além de garantir os direitos à verdade, à justiça e à reparação das vítimas, tanto pela via administrativa como judicial. Vincula-se a ela o Decreto 1.290, de 2008, para os trâmites de reparação. 
${ }^{6}$ O Banco de la Esperanza é um dos projetos sobreviventes da onda de iniciativas que chegou a Urabá após os deslocamentos massivos de pessoas das áreas mais próximas à fronteira com o Panamá e do meio rio Atrato no departamento de Chocó, cujos efeitos devastadores foram mais perceptíveis a partir do começo do século XXI. O Banco de la Esperanza, que funciona como um fundo rotativo solidário, surgiu em 2003 por iniciativa da Oxfam, e contou com o apoio logístico da Pastoral Social da Diocese de Apartadó. As Hermanas de San Juan Evangelista, por sua vez, encarregaram-se do gerenciamento do projeto desde 2004.

${ }^{7}$ Um dos seus equivalentes no Brasil é o SERASA.

${ }^{8}$ A partir do conjunto de 25 visitas realizadas, foi possível construir um perfil dos clientes do Banco de la Esperanza. A maioria dos beneficiários era de mulheres chefes de família; neste caso, 19 mulheres e seis homens. Os empreendimentos propostos consistiam no abastecimento de marcenarias e camelôs e na venda de arepas, tamales, fritos, peixe, galinhas, queijo, plátano e chapéus, jogos de cama, roupas, bijuterias e cosméticos. Além dos empreendimentos baseados na elaboração e venda de tamales, arepas e fritos, somente duas pessoas empregaram o crédito na manufatura de mercadorias (sapatos e roupas). Em relação à classificação étnica, 13 pessoas identificaram-se como negro, chocoano e afrocolombiano, oito se definiram como chilapo - vinculado às populações do departamento de Córdoba, principalmente - e quatro disseram ser paisas - das regiões meridionais de Antioquia (ver Monroy 2013 para uma discussão mais ampla). Quanto à vinculação religiosa, 12 eram cristãos e somente uma pessoa fez questão de identificar-se como católica "praticante". Entretanto, as 12 restantes preferiram não se enquadrar nessas categorias, embora seis pessoas deste grupo afirmassem gostar de assistir aos cultos e jejuns das igrejas cristãs. Contudo, elas reiteraram "gostar do evangelho". É importante levar em consideração que as pessoas "do evangelho", resistentes à denominação "evangélico", informaram as igrejas em que se congregavam. A diversidade destes centros é impactante: 12 pessoas, algumas delas vizinhas de rua, chegaram a registrar oito igrejas diferentes.

${ }^{9}$ Considero que o marco interpretativo do "Ensaio sobre a Dádiva" confirma a existência de princípios que operam na vida social e não somente nos tipos de sociedades considerados o "objeto" diferenciado das especialidades universitárias. Assim, o estudo de sociedades com sistemas de intercâmbio não mercantis, por exemplo, costuma ser considerado um objeto "reservado" da antropologia. Aliás, ainda que Lévi-Strauss (2005) [1950] tenha afirmado que as "três operações discretas que a vida social decompõe" são aspectos subsidiários quando comparados com a troca propriamente dita, ele reconhece que tais operações são um canal de entrada que pode permitir a compreensão de certos fenômenos sociais. A minha trajetória, neste texto, é conduzida por esta possibilidade.

${ }^{10} \mathrm{O}$ tempo de devolução, no modelo proposto por Mauss, é um elemento fundamental, pois é um tempo eminentemente social, passível de particularização etnográfica e, portanto, um termômetro do elo social. 
${ }^{11} \mathrm{Na}$ minha leitura do "Ensaio sobre a Dádiva", o circuito constituído pelos atos de dar, receber e retribuir inicia-se com o reconhecimento de igualdade das partes envolvidas, levando em consideração que, no caso das prestações totais, não são os indivíduos que se obrigam, trocam e contratam, mas sim as coletividades por meio de pessoas morais. Apesar de estarem implícitos desejos de prestígio, hierarquia e lucro, a dinâmica da dádiva precisa do reconhecimento inicial de uma igualdade em dignidade das partes envolvidas, sendo um requisito relativo à obrigatoriedade das relações sociais. O modelo de Mauss fundamenta-se, assim, nos imperativos morais contra o isolamento e o ostracismo que impedem a reprodução social.

${ }^{12}$ Ver Monroy (2013) para uma caracterização mais ampla dos paisas, na qual examino a relação entre a hegemonia econômica atribuída a eles e algumas diretrizes e concepções étnicas e ideológicas que os identificam.

13 "Regar", na forma utilizada pelos interlocutores, tem dois sentidos: molhar ou aguar a terra, e espalhar. No caso do verbo "espalhar", usa-se no sentido de espalhar sementes.

${ }^{14} \mathrm{O}$ alvo do extermínio são ladrões, drogados e prostitutas. Em alguns casos, o alvo também inclui - e assim é explicitado nos pasquins e nas "listas negras"- colaboradores do grupo armado opositor, infiltrados e delatores, estes últimos conhecidos como sapos.

${ }^{15}$ Durante o trabalho de campo, muitas pessoas - e não somente os ex-combatentes, mas até mesmo crianças - destacaram o "caráter guerreiro do povo de Urabá", isto é, dos homens de Urabá, vinculado às armas e à luta pelo território (ver Monroy 2013). O sujeito pensa-se "guerreiro" porque Urabá tem sido cenário de várias guerras e "criou homens para a guerra" que se espalharam pelo país inteiro. A partir dessas considerações, é possível falar de um "ethos guerreiro", isto é, uma constante pervasiva e inescapável das sequências e das etapas de vida masculina, em que a adesão a um perfil guerreiro de uma organização inevitavelmente se segue à outra adesão em outro movimento, grupo armado ou bando.

${ }^{16}$ Esse princípio pode ser resultado também de ações que buscaram mitigar as crises durante toda a década de 90 até 2004, quando começou a desmobilização dos blocos das AUC que atuaram na região.

${ }^{17}$ Conforme relatório de outubro de 2010, 4.792 famílias receberam a indenização solidária no departamento de Antioquia, das quais 2.519 eram de Urabá. A entrega de novas indenizações a 2.060 famílias em Antioquia, das quais 561 eram moradoras de Urabá, aconteceria antes do final de 2010. Além disso, enfatiza-se nas verbas transferidas, pois mais de 100 mil milhões de pesos foram destinados à região. Cf. http://www.accionsocial.gov.co/contenido/contenido.aspx? conID=5207\&catID=127. Acesso em: 15/05/2011.

${ }^{18}$ Este tipo de reparação individual é denominado indenização solidária. No decreto são feitas as especificações em relação à quantia da indenização: ho- 
micídios e desaparição forçada e sequestro, 40 salários mínimos mensais legais; lesões pessoais e psicológicas que produzam incapacidade permanente, 40 salários mínimos legais; lesões pessoais e psicológicas que não incorram em incapacidade permanente, 30 salários mínimos legais; no caso de tortura, 30 salários mínimos mensais legais. Nos casos de delitos contra a liberdade e a integridade sexual e recrutamento ilegal de menores, 30 salários mínimos legais. Para o delito de deslocamento forçado (desplazamiento forzado) contempla-se o pagamento de 27 salários mínimos mensais legais.

${ }^{19}$ Voltando a Mauss, o caráter paradoxal da dádiva está presente no objeto (foco da troca), pois ele contém a semente da hierarquização, assim como também um caráter de individuação que vai se tornando mais amplo à medida que as instituições jurídicas se separam, isto é, quando o dom deixa de ser uma prestação total. De qualquer forma, esse caráter de individuação possui um componente de igualdade que é resumido por Mauss nos postulados "algo de nós permanece nos outros" e "algo dos outros permanece em nós". As categorias hau e mana correspondem ao espírito que acompanha o donatário, embora pertençam ao doador, pois o objeto está impregnado dele. Por isso, o objeto é perigoso. Mana, por sua vez, faz referência à autoridade, à honra e à fonte de riqueza. Por fim, hau refere-se ao componente de individuação; entretanto, na categoria mana há elementos relativos à hierarquia social e às possibilidades de hierarquização.

${ }^{20}$ Ver Godbout (1999) para uma discussão mais ampla sobre reciprocidade, dádiva e mercantilização.

${ }^{21}$ Ver Aretxaga (1997) para a relação entre tempo, territorialidade, gênero e violência, e Palmeira (2001) para uma reflexão sobre tempo, ordem social e adequação de comportamentos entre populações camponesas do Nordeste brasileiro.

${ }^{22}$ Autores da música: Jorge Luis Piloto e Jorge Villamizar.

${ }^{23}$ Para que pensar e supor, não perguntes coisas que não sei, eu não sei/ Para que jurar e prometer uma coisa que não está em nosso poder/ Eu não sei o que é eterno, não me peça algo que é do tempo/ Eu não sei amanhã, eu não sei amanhã/ Quem vai estar aqui 


\section{Referências bibliográficas}

ARENDT, Hannah. 1978. O sistema totalitário. Lisboa: Publicações Dom Quixote. ARETXAGA, Begoña. 1997. Shattering silence: women, nationalism, and political subjectivity in Northern Ireland. Princeton: Princeton University Press. CAILlÉ, Alain. 2002. Antropologia do dom: o terceiro paradigma. Petrópolis: Vozes.

CRAPANZANO, Vincent. 1986. Waiting. The whites of South Africa. New York: Vintage Books.

ETZIONI, Amital. 1988. The moral dimension: toward a new economics. New York: The Free Press.

GARCÍA, Clara Inés. 1996. Urabá: región, actores y conflicto 1960-1990. Bogotá: CEREC/INER (Universidad de Antioquia).

GODBOUT, Jacques. 1999. O espírito da dádiva. Rio de Janeiro: Fundação Getúlio Vargas.

HUMAN RIGHTS WATCH. 2012. Herederos de los paramilitares. La nueva cara de la violencia en Colombia. Relatório anual.

LÉVI-STRAUSS, Claude. 2005 [1950]. "Introdução à obra de Marcel Mauss". In: Sociologia e antropologia. São Paulo: Cosac Naify. pp. 11-46.

LOMMINTZ-ADLER, Claudio. 2003."Times of crisis: historicity, sacrifice, and the spectacle of debacle in Mexico City". Public Culture, 15(1):127-147.

MAUSS, Marcel. 1971 [1923]. "Ensayo sobre los dones: razón y forma del cambio en las sociedades primitivas". In: Sociología y antropología. Madrid: Tecnos. pp. 153-263.

MONROY, Silvia. 2013. El presente permanente. Por una antropografía de la violencia a partir del caso de Urabá, Colombia. Bogotá: Universidad Del Rosario (com versão eletrônica, e-book).
PALMEIRA, Moacir. 2001. "Política e tempo: nota exploratória". In: M. Peirano (ed.), O dito e o feito: ensaios de antropologia dos rituais. Rio de Janeiro: Relume Dumará. pp. 171-178.

SÉMELIN, Jacques. 2009. Purificar e destruir: usos políticos dos massacres e dos genocídios. Rio de Janeiro: Difel/ Bertrand Brasil.

STRATHERN, Marilyn. 2006 [1988]. O gênero da dádiva: problemas com as mulheres e problemas com a sociedade na Melanésia. Campinas: Editora Unicamp.

SUÁREZ, Andrés Fernando. 2007. Identidades políticas y exterminio recíproco: masacres y guerra en Urabá 1991-2001. Medellín: La Carreta/ IEPRI (Universidad Nacional de Colombia).

TAMBIAH, Stanley J. 1996. Leveling crowds. Ethnonationalist conflicts and collective violence in South Asia. Berkeley: University of California Press.

TAUSSIG, Michael. 1987. Chamanismo, colonialismo y el hombre salvaje: un estudio sobre el terror y la curación. Bogotá: Grupo Editorial Norma. 


\section{Resumo}

Comparo, neste texto, a modalidade de empréstimo de dinheiro imposta pelos "gota a gota" com a minha experiência como voluntária no Banco de la Esperanza, em Urabá, considerada uma das regiões mais violentas da Colômbia durante, pelo menos, quatro décadas. Mediante este contraste, passo a analisar a relação entre o que denomino "presente permanente" e determinados aspectos da troca, a saber: "o costume de ficar devendo", "a necessidade de pedir emprestado", e o imperativo de que "tudo deve ser dado". No caso estudado, tais efeitos são aspectos primordiais da vida coletiva e da reprodução social. Busco, em particular, explorar a relação entre violência e "economia", vínculo que costuma ser relegado ao campo da ilegalidade.

Palavras-chave Violência, Tempo, Troca, Urabá, Colômbia.

\section{Abstract}

In this paper, I compare the financial loan method of the "drop by drop" system with my experience as a volunteer at the Banco de la Esperanza in Urabá, a region that has been, for at least four decades, considered one of the most violent regions of Colombia. Through this comparison, I proceed to analyze the relationship between what I call the idea of "permanent present" and certain aspects of the exchange, namely: "the habit of owing people money", "the need to borrow money" and the imperative that "everything must be given for free". In my case study, these effects represent fundamental aspects of community life and social reproduction. My specific aim is to explore the relationship between violence and economics, which is usually relegated to the realm of illegality.

Key words Violence, Time, Exchange, Urabá, Colombia. 